\title{
Approaches to the Teaching of Translation
}

\author{
M. Carmen África Vidal Claramonte \\ Universidad de Salamanca
}

\begin{abstract}
Translation Studies have only recently begun to be considered as an independent discipline. Many questions remain unanswered. One which has not received much attention is that connected with the teaching of translation. The aim of this essay is to suggest some ideas concerning this issue, taking first into account the qualities of the translator, his social and cultural background, etc. The essay also considers the question of reading a text well and offers some suggestions for exploitation of this subject and others in the classroom.
\end{abstract}

Even though man has, from the beginning of time, always translated in one way or another, Translation Studies have only recently begun to be considered as an independent discipline. Translators are now being trained at specialised faculties, since they are thought to have an essential function in international meetings, institutions, etc. However, this renaissance of translation as an autonomous and important field of studies mainly during the 1980s still poses many questions: quite a large number of books are published today on the subject of translation, but, as scholars argue, there are clearly huge gaps "between the needs of translation pedagogy and that which is offered by a theory, which has hardly started to realize the necessity to cater for the specific requirements of its applied extensions" (Toury 188). In fact, the didactics of translation is perhaps the area of Translation Studies which has received less attention: "the teaching of translation has been seriously impeded by what can only be described as a great gulf between translation theory and practice. On the one hand, students express frustration at being burdened with theoretical considerations (both translation theory and general linguistics) which they feel have nothing to do with the activity of translating, and on the other hand scholars talk scathingly of translators who are unwilling to investigate the theoretical basis of their work, thus reducing it to a 'mere practical skill"' (Snell-Hornby 105). It goes without saying that this essay does not intend to give a "magic" recipe for teaching translation. I will only try to give some hints which, I hope, may be useful to train translators. 
The first thing one should take into account when teaching how to translate a text is to examine the qualities of the translator. No doubt, the main quality should be that the translator have a perfect knowledge of the target language, which must always be his mother tongue. This first attribute of the translator-to know perfectly well the language into which he is going to translate-seems to have been underlined by all scholars, from Dryden to Nida (see Dryden, Nida, and Benítez). This, which could apparently be seen as an obvious requirement, is sometimes not so obvious: one remembers Milan Kundera's astonishment when he met his first translator into English. The writer asked him how he had dared to attempt such a translation when he had no idea of English. The translator produced a photo of his idol and answered: "With my heart."

The second attribute of a translator is that he must have a perfect knowledge of the social and cultural background-literature, arts, history, politics, etc.-of the two cultures involved. This is especially true in the case of literary, philosophical or artistic texts. The translator, says Nida, must have "the gift of mimicry, the capacity to act the author's part, impersonating his demeanor, speech, and ways, with the utmost verosimilitude" (Nida 151).

The translator must also be both humble (so that he does not correct the author) and distrustful (he must check all doubtful terms). Furthermore, he should be able to hear the music of the target text, the different registers and styles, and he should be careful not to change that style and substitute it for his own idiolect, since "like the original poet, the translator is a Narcissus who in this case chooses to contemplate his own likeness not in the spring of nature but in the pool of art" (Poggioli 139).

On the other hand, the teacher of translation must also have some attributes. It is essential that the teacher is also a translator. He must have been through the same or similar situations as the student goes through when engaged with a translation and he must know how the world of translation works. The teacher should also put the student in contact with the main associations and conferences connected with translation, both in his country and abroad, and with the main journals (Babel, Meta, Target, etc.).

It goes without saying that teachers of translation, when elaborating their programmes, must also decide what kind of knowledge and what kind of competence he is to teach the student. The situation in the Faculties of Translation is different from that in the Departments of English Studies. The programme of Translation Studies must take into account the needs of contemporary society: the increasing demand for translators in some fields-for instance, technology, law, economy, medicine, dubbing, etc. Thus, the curriculum should include such subjects as cultural studies on the organization of political, cultural or social institutions of the country of the target language, and some others connected with the functioning of international organizations such as the UN or the EEC. Other subjects in the curriculum should include the teaching of technical terminology and specialized jargon, text analysis, etc.

The analysis of texts, reading well-especially literary texts and texts on aesthetic theory -is, in my view, extremely important to translate well. The student should be taught to read carefully, to be sensitive to different styles, registers, writing techniques, etc. If he is able to read well, he will look for phrases which are repeated or which are typical of that author. He will underline the terminology used, the register, proverbs, style, grammar, 
intention of the text, intertextual elements, modality of discourse, punctuation, use of toponims, titles of films or books, alliterations, etc. Thus, I would like to propose here some aspects which should be taken into account if one wants to read a text carefully; these aspects are summarized in the following scheme by Enrique Alcaraz:

\section{Conditions of Textuality}

- meaning and significance

- coherence

- cohesion

- progressivity

- closure

- intentionality (tone --register and aim of discourse- and attitude)

\section{Types of Attitude}

1) personal (active sentences)

2) impersonal (passive sentences)

3) neutral (epistemic forms)

4) engaged (deontic forms)

\section{Attitude Imprints}

1) organizing patterns

2) modality (deontic, taxative, tentative)

3) disjunctive adverbs (e.g. "obviously")

4) focalization (post-position, fronting, inversion, discontinuity)

II. Modality of Discourse

A) DESCRIPTION

1) presentation through the senses

2) use of names and adjectives

3) adjectival clauses

4) -ing forms

5) compound words

6) verbs of duration

7) non-verbal elements (kinesic channels, paralinguistics, voice qualities, voice qualifications, vocalizations, etc.)

8) use of details (order, quantity, and quality)

9) vividness (it is achieved thanks to: details, appeal to the senses and figurative language)

B) EXPOSITION

Information is presented through our intellect

1) use of definitions (logical and rhetorical definitions)

2) classification and division (systematic thought, structure)

3) use of examples 
4) comparisons and contrasts

5) cause and effect (see links between the sentences)

6) analysis of process (assuming, sense of audience)

7) impersonal pronouns

8) passive

9) place and character

10) argument and persuasion

11) illustrated maxims

C) NARRATION

Point of view:

1) 1st person

2) 3rd person

3) omniscient narrator

4) intrusive narrator

5) several narrators

6) fringe narrator

7) interior monologue

8) distance between character and reader

Unlimited point of view:

9) epistolar novel

10) combined point of view (1st +3 rd person; past + present tense)

11) linked point of view (several 1st person narrators + authorial intrusion or 3 rd person narrator)

12) bouncing (use of adverbs or adverbial clauses, verbs denoting action or movement, simple past and past perfect, generalized, summarized, dramatic, distance, direct and indirect speech)

\section{Meaning and Significance}

1) implication

2) connotation

3) presupposition

4) key words

5) witness words

6) stylistic themes: the repetition of harmonics (stylistic themes) creates a psychological atmosphere (irritation, tension, etc.)

7) thematic or topic sentences

8) theme/rheme

9) register

\section{Significative Resources}

\section{A) STYLISTICS OF CHOICE}

- inclusion/exclusion of certain elements

- it may be caused by : (1) the contents; (2) the writer's way of being (living), 
experience, or socio-cultural background; (3) aim of the message (to inform, to persuade, to instruct, etc.)

- motives: main points of interest consciously chosen by the author. He develops the whole narrative web around them. One notices them because of the repetition of certain elements which are developed with illustrations, definitions, etc. Thematic Choice: Dimensions

a) Thematic Preferences: theme (developed through semic accumulation)

b) Semic Loads: appearance of a sentence with several thematic semes (this makes tension grow)

c) Articulators of Experience: words chosen by the writer to construct experience around them.

d) Centers of attention: lexemes constituting the main point of attention for the author.

e) How to show experience: theme/rheme, reification

B) STYLISTICS OF DEVIATION

- metaphor (intralinguistic/extralinguistic)

- simile

- comparison

- contrast/identity

- personification

- synaesthesia

- metonymy and synecdoche

- synonymy

- alliteration

- onomatopoeia

C) STYLISTICS OF EXPRESSIVITY

1) Connotation of the langue (stable features)

- words which have been hypostatized into a symbol (e.g. fire stands for passion or love; water for purity or life, etc.)

- words which have not been turned into symbols (e.g. "glee" means "feeling of joy," but it connotes triumph, success, etc.)

2) Connotation of the parole (occasional features) (e.g. "beady" means small, round and bright, but it may connote hostility)

3) Cultural connotation (e.g. "drunk," "ambitious," etc.)

$V$. The writer's point of view

- Direct/Indirect style

- Point of View

VI. Tone and Attitude

- Irony

- Satire, etc. ${ }^{1}$ 
If the translator takes into account all these aspects of a text, he will be able to read that text correctly and, as a consequence, to translate it well.

The main aim of the teacher of translation should be to train professionals who will, in the future, earn their living as translators. Therefore, he should make the student aware of the fact that translation is not an innocent act. It is, rather, a hermeneutic process, an ontological decision, a re-writing, a re-reading of two cultures, of two his-stories. These re-writings are, in most cases, unbalanced: one of the cultures is more powerful and decides what, how, when, to translate. Looking at the different elements suggested above for the analyses of texts, one realises that translation implies manipulation, since different parts of the text may be foregrounded, with different effects. Different values, different scales, different sets of norms. One may accept that difference; one may want to naturalize that difference: "a labor of acculturation which domesticates the foreign text, making it intelligible and even familiar to the target-language reader, providing him or her with the narcissistic experience of recognizing his or her own cultural other" (Venuti 5). We need to train what Toury calls "native translators," who gradually assimilate the background, context, and norms of the target language: "Each type of situation should produce a different set of constraints and norms. Consequently, the greater the variety of situations that a translator is put into, the greater the range and flexibility of his ability to perform, or adapt himself to changing norms is going to be" (Toury 191). The student should therefore gradually achieve a mixture of nature and nuture, since he will have to translate taking into account the cultural and semiotic context. Whereas the competent bilingual speakers will only offer an interlinguistic equivalence, the native translator will be able to assess the norm-governed translation equivalence. That is why travelling abroad is so important for the student of translation. This is nowadays quite easy with the ERASMUS and LINGUA programmes, for instance, which make things easier. Living in the target culture is the only way to understand and acknowledge its norms, politics, aesthetics, institutions, etc. This will help extraordinarily when having to translate any kind of text, from a booklet to a legal text. To do a good job, the translator must achieve what Jauss calls "the historical distance between the alien horizon of the text and the horizon of the interpreter" (Jauss 197).

Apart from convincing the student of the importance of analysing and reading the text carefully before translating it and of the relevance of knowing well the target culture, the teacher must decide which methodology he wants to choose, top-bottom or bottom-top, always taking into account that both methods have pros and cons. Furthermore, translation is not, cannot be, an exact science to which preconceived formulae can be applied. Thus, perhaps it is better to use one methodology or the other according to the text, background of students, etc.

The teacher of translation should never impose his perspectives. Rather, he is expected to ask the student why he has translated in a particular way, what decisions he has taken, and how he has reached that result. In that way, the student will develop his linguistic taste, his critical capacity and his own ways of evaluation. Extracurricular activities may be a good contribution to this, since the student will, through lectures, conferences, roundtables, workshops, etc., open his mind to new and different points of view.

Some interesting exercises are to comment translations: i.e., the student writes footnotes for each word of the original text he thinks may be difficult to translate. In that 
footnote, he should say why he thinks that word or phrase is complex (sociological, cultural, grammatical, etc., differences between the original language and the target language). This exercise helps students check every single word, to analyse it, to reflect on it, to think about what problems it might pose when translated.

It is also useful to compare texts which deal with the same topic in both languages. These texts may be taken from magazines, newspapers, journals, etc. Thus, students become familiar with the vocabulary usually used for a particular issue and, on the other hand, they acquire a better knowledge of the topic they are to translate. Another exercise that could be used is to give students a text which has already been translated into their TL. If possible, the teacher should provide them different translations of the same text and ask students to study them, propose changes, but, most important, justify those changes. The putting together of all the comments and analyses of the students helps increase their critical capacities.

Speed translation and sight translation are also good exercises to check and improve the student's mother tongue, his vocabulary, capacity of synthesis, etc. Shadowing and the so-called mirror effect are equally useful to prepare them for future situations as professional translators.

It goes without saying that the exercises proposed here for the teaching of translation will not solve all the situations in which the student will be involved when he is a professional in the real world. How will he manage if asked to translate Walter Abish's Alphabetical Africa, where each chapter begins with a letter of the alphabet (first chapter, A, all words begin with the letter $a$; second chapter, all words begin with $a$ and $b$, and so on)? Most probably, we, teachers, will never be able to give answers, but we can ask questions, and this may help our students. In any case, even though we know the task of the teacher of translation is impossible, we know we can't go on, we must go on.

\section{Note}

1. Based on lecture notes by Enrique Alcaraz, and to be published in English Literary Discourse.

\section{Works Cited}

Alcaraz Varó, Enrique. English Literary Discourse. In preparation.

Benítez, Esther. "El traductor literario." Letra Internacional 30/31 (1993): 39-40.

Dryden, John. "On Translation." Theories of Translation: An Anthology of Essays from Dryden to Derrida. Eds. Rainer Schulte and John Biguenet. Chicago and London: U of Chicago P, 1992. 17-31.

Jauss, Hans Robert. Question and Answer: Forms of Dialogic Understanding. Minneapolis: University of Minnesota Press, 1989.

Nida, Eugene A. "Basic Requirements for the Translator." Toward a Science of Translating with Special Reference to Principles and Procedures Involved in Bible Translating. Leiden: Brill, 1964. 150-52. 
Poggioli, Renato. "The Added Artificer." On Translation. Ed. R. A. Brower. 1959. New York: Oxford UP, 1966.

Snell-Hornby, Mary. "Dimension and Perspective in Literary Translation." Wilss and Thome 105-13.

Toury, Gideon. "The Notion of 'Native Translator' and Translation Teaching." Translation Theory and its Implementation in the Teaching of Translating and Interpreting. Eds. Wolfram Wilss and Gisela Thome. Tübingen: Narr, 1984. 186-95.

Venuti, Lawrence. Introduction. Rethinking Translation: Discourse, Subjectivity, Ideology. Ed. Lawrence Venuti. London: Routledge, 1992. 